\title{
Design and Evaluation of Piezoelectric Ultrasonic Scaler Produced by a Simulation
}

\author{
김철민 ${ }^{1,2}$, 이영진 ${ }^{1, a}$, 백종후 ${ }^{1}$, 정영훈 ${ }^{1}$, 강국진 $^{3}$, 이정배 $^{4}$, 이승대 ${ }^{4}$ \\ (Chul-Min Kim ${ }^{1,2}$, Young-Jin Lee ${ }^{1, a}$, Jong-Hoo Paik', Young-Hun Jeong ${ }^{1}$, Kook-Jin Kang ${ }^{3}$, Jeong-Bae Lee ${ }^{4}$, \\ and Seung-Dae Lee $^{4}$ )
}

\begin{abstract}
A piezoelectric ultrasonic scaler, usually used to remove the tartar out of teeth and to amputate the pubis, is a recently popular instrument for dental treatment due to its several merits such as small size, low-electric power, precision and low-cost. It has typically two parts of a tip and vibration system, which is also composed of head, piezoelectric elements and tail-mass. The scaler concentrates its displacement on tip and has commonly a resonance frequency at $25 \sim 30 \mathrm{kHz}$, and in order to improve the performance of the scaler, it is important to standardize the size of the vibration system without tip for high performance because scaler in quality differs according to several tips. In this study, a Finite Element Analysis (FEA) was utilized to optimize the structure of ultrasonic scaler in the vibration system. Consequently, this study revealed that influence of several tips on property were minimized and scaler showed good property at the resonance frequency of $28 \mathrm{kHz}$.
\end{abstract}

Key Words : Scaler, PZT, Actuator, Simulation, Frequency, Displacement

\section{1. 서 론}

치아의 치석 제거 및 치료용 도구로 사용되는 초음파 스케일러(Ultrasonic Scaler)는 초음파를 발 생시키는 음원에 따라 자왜형(Magnetostrictive), 압전형(Piez oelectric) 및 기계형(Pneumatic) 방식 으로 분류된다. 자왜형과 기계형은 장시간 사용 시 발열의 문제가 있고 미세출력 조절, 소형화가 어려 운 단점이 있다[1]. 압전형은 전계를 인가하였을 때 변위가 생기는 액츄에이터 (Actuator)형식으로

1. 한국세라믹기술원 광 - 전자세라믹본부 전자부품센터 (서울시 금천구 가산동 233-5)

2. 연세대학교 신소재공학과

3. 한국섬유기계연구소 설계기술팀

4. (주)디메텍

a. Corresponding Author : yjlee@kicet.re.kr

접수일자 : 2009. 7. 16

1차 심사 : 2009. 8. 13

심사완료 : 2009. 9. 11
고장율이 적고 다른 방식에 비해 장시간 사용시 발열이 적으며, 미세 파워 조절 및 몰딩 구조로 만 들기 용이한 장점을 통해 최근 들어 압전형 초음 파 스케일러의 사용이 증가하고 있다[2,3]. 이러한 압전형 초음파 스케일러(Piezoelectric ultrasonic scaler)는 시술자가 용이하게 의료 시술을 할 수 있어야 하며, 부하의 조건변화에 따라 초음파 진동 자의 진동 주파수(Frequency)를 능동적으로 가변 할 수 있어야 한다. 이때 초음파 주파수는 같은 부 하에서는 일정 진동을 유지되어야 하는 컨트롤 알 고리즘이 필요하고 진동자의 주변 환경(부하변동, 주변 온도변화, 습도변화 등)에 따라 최적의 제어 가 될 수 있는 제어 알고리즘이 필요하다.

본 연구에서는 유한요소해석을 이용하여 보다 향상된 스케일러의 구현을 위해서, 압전 세라믹 및 SUS 재질의 Head, PZT, Tail 부로 구성된 스케일 러 구성품의 형성변화에 따른 중심주파수 및 출력 변위의 경향분석을 실시하였으며, 이를 바탕으로 
$28 \mathrm{kHz}$ 에서 최대 출력변위를 얻을 수 있는 최적의 스케일러 구조를 도출하기 위한 연구를 진행하였 다. 또한 앞서 언급한 압전형 초음파 스케일러에 대한 요구사항을 고려하여 제작 및 평가하여 시뮬 레이션의 유효성을 검증하였다.

\section{2. 스케일러 이론 및 설계}

\section{1 압전 액 츄에이터(Piezoelectric actuator)}

압전형 초음파 스케일러는 일반적으로 적층형 액츄에이터 방식을 진동자 소자로 사용하여 발생 력이 크고 미세한 출력변위가 제어가 가능하며, 형 태의 영향이 적어 시술자에 요구에 맞게 조절할 수 있는 장점이 있다[4]. 액츄에이터란 어떠한 가 동에너지를 기계적인 변위 또는 응력으로 변환하 는 트랜스듀서(Transducer)의 의미로써, 적층형 액 츄에이터의 발생 변위 $X$ 는 압전판의 적층수 $N$, 인 가전압 $V$, 종효과 압전정수를 $d_{33}$ 로 할 경우,

$$
x=N d_{33} V
$$

식 (1)으로 구할 수 있다[4]. 압전판 1 개 당의 변위 량이 적을 경우에는 적층수를 늘리면 변위량도 비 례하게 증가하고 액츄에이터의 길이를 $L$, 횡방향 단면적을 $S$, Young's modulus를 $Y_{33}{ }^{E}$ 라 하면, 발 생력 $F$ 는

$$
F=N\left(\frac{S}{L}\right) Y_{33}^{E} d_{33} V
$$

와 같이 된다[4]. 적층형의 변위량은 압전판의 두 께와는 무관하기 때문에 두께를 얇게 하고 적층 방향의 치수를 일정하게 유지하도록 적층 수를 늘 리면, 동일한 발생변위를 낼 수 있는 구동전압을 낮출 수 있다.

\section{2 스케일러의 주파수 결정}

압전형 초음파 스케일러(Piezoelectric ultrasonic scaler)의 압전 세라믹은 스케일러의 길이방향인 전후로 진동하지만 진동부의 끝부분이 고정되어 있어 모든 진동출력이 팁 끝단에 모이게 되고, 이 때 팁의 변위를 이용하여 치석을 제거하는 원리를 가지고 있으며 각 구성품의 디자인에 따라 주파수 와 팁에서의 진동 출력특성을 미세하게 조절할 수 있는 장점을 가지고 있다. 이때 스케일러의 주파수 를 구하는 식은 다음과 같다[5].

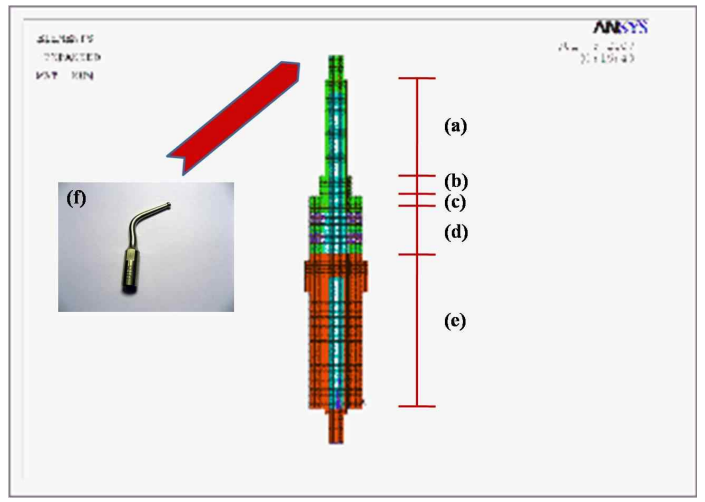

그림 1. 진동부의 모델링.

Fig. 1. A modelling of the vibration system.

(a) Head1 (b) Head2 (c) Head3 (d) PZT (e) Tail (f) Tip

$$
f=V / \lambda
$$

$\mathrm{V}:$ velocity, $\mathrm{f}:$ frequency, $\lambda$ : wavelength

특히 의료기기(치과용)으로 사용되는 초음파 스 케일러는 일반적으로 높은 출력을 얻기 위하여 낮 은 주파수 대역을 가져야 한다. 하지만 가청영역의 주파수인 $20 \mathrm{kHz}$ 이하로 떨어지게 되면 소음으로 인하여 실제 사용하는데 큰 어려움이 있기 때문에 주로 $25 \sim 30 \mathrm{kHz}$ 대역에서 사용된다[6].

2.3 유한요소 해석(FEA : Finite element analysis) 을 통한 스케일러 기본설계

스케일러는 그림 1 과 같이 진동부와 팁으로 이 루어져 있지만 시술자의 사용용도(의료기기용)에 따라 팁은 여러 종류로 나뉘기 때문에 팁 자체를 규격화 한다는 것은 매우 어려운 일이다[7,8]. 그러 므로 팁의 영향을 적게 받는 최적의 진동부를 설 계하기 위해 본 연구에서는 유한요소 상용 해석 소프트웨어인 ANSYS를 이용하여 각 구성품 Head1, Head2, Head3, Tail의 사이즈를 정하고 10 $\mathrm{mm}$ 의 직경과 $2 \mathrm{~mm}$ 의 두께를 가지며 한국세라믹 기술원에서 개발한 PZT[9]의 물성을 사용하여 그 림 1 과 같이 현재 많이 사용되고 있는 스케일러의 형상으로 모델링 하였다.

시뮬레이션을 이용하여 모델링 된 스케일러 진 동부의 고유주파수를 해석하여 $43.9 \mathrm{kHz}$ 의 공진주 파수를 가지는 것을 확인하였고 식 (3)을 이용하여 이론적 주파수를 비교한 결과, 시뮬레이션 결과와 비슷한 대역 $(44 \mathrm{kHz})$ 의 주파수를 가지는 것을 확인 


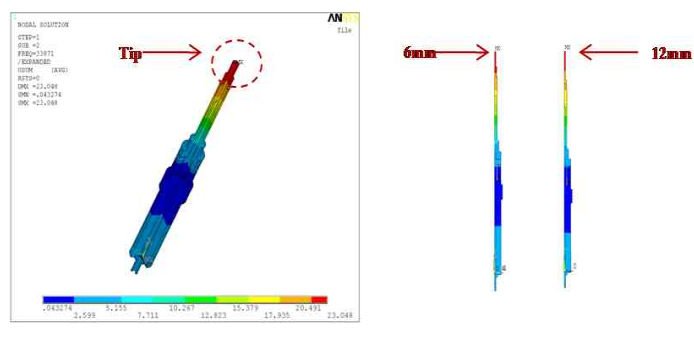

그림 2. 팁이 부착된 스케일러의 시뮬레이션.

Fig. 2. Simulation of scaler with tip.
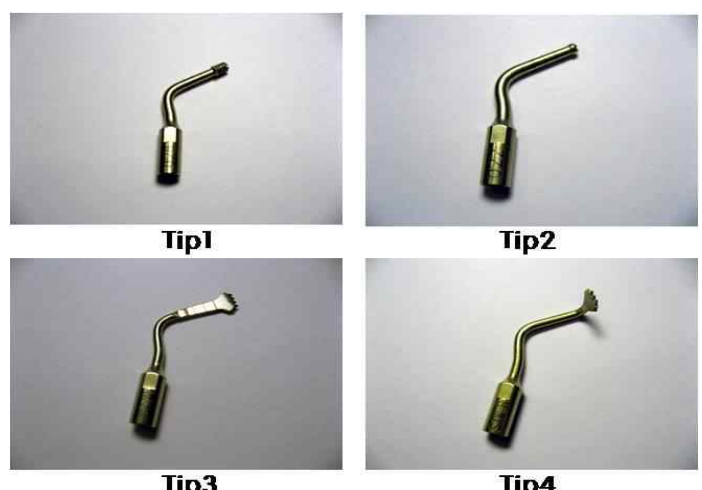

그림 3. 팁의 길이와 형상에 따른 종류.

Fig. 3. A kinds of tip by its length and designs.

하였다. 하지만 앞서 언급한 바와 같이 팁 부착 시 스케일러에 미치는 영향을 비교하기 위하여 그림 2 와 같이 팁 부분을 추가로 모델링하여 특성변화 를 살펴보았다.

그 결과 팁의 형상과 길이 등의 종류(그림 3)에 따라 스케일러 진동부에 팁을 부착 시켰을 때의 주파수에 따른 임피던스 측정을 그림 4 에 나타내 었다. 그림 4 의 결과 스케일러에 부착 된 팁의 부 하영향이 약 $30 \%$ 정도로 크게 나타나는 것을 알 수 있었다. 현재 사용자의 요구에 따라 많이 사용 되고 있는 여러 팁들의 길이를 축소한다는 것은 가공성, 내구성 등의 요소들로 인해서 현실적으로 불가능하고 팁의 끝 모양 역시 그림 3의 종류보다 훨씬 다양하기 때문에 팁의 영향을 받지 않도록 스케일러의 진동특성에서 팁의 부하효과를 감소시 켜야 한다.

따라서 본 연구에서는 $28 \mathrm{kHz}$ 주파수 대역에서 최고의 출력변위를 얻기 위해서 시뮬레이션을 통

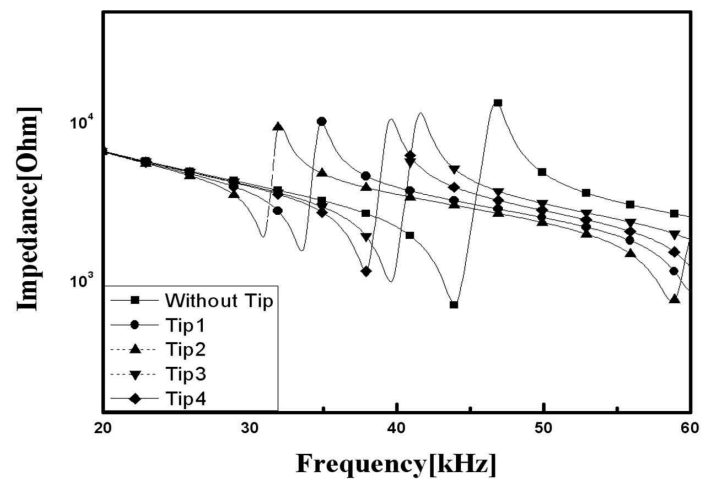

그림 4. 팁에 따른 주파수 변화(시뮬레이션).

Fig. 4. Changing of frequency by several tips (Simulation).

표 1. 스케일러의 디자인 변화에 따른 경향.

Table 1. A tendency by changing the design of scaler.

\begin{tabular}{|c|c|c|c|}
\hline & $\begin{array}{c}\text { Length } \\
{[\mathrm{mm}]}\end{array}$ & $\begin{array}{c}\text { Frequency } \\
{[\mathrm{kHz}]}\end{array}$ & $\begin{array}{c}\text { Displacement } \\
{[\mathrm{mm}]}\end{array}$ \\
\hline Head1 & $\uparrow$ & $\downarrow$ & $\downarrow$ \\
\hline Head2 & $\uparrow$ & $\downarrow$ & $\downarrow$ \\
\hline Head3 & $\uparrow$ & $\downarrow$ & $\downarrow$ \\
\hline Tail & $\uparrow$ & $\downarrow$ & $\downarrow$ \\
\hline
\end{tabular}

한 최적구조를 도출하였다. 도출된 구조는 앞에서 얻은 결과를 바탕으로 팁의 길이를 $16 \mathrm{~mm}, \mathrm{PZT}$ 직 경을 $10 \mathrm{~mm}$ 로 고정하여 진동부의 Head1, Head2, Head3 및 Tail의 형상을 ANSYS 시뮬레이션을 이용 하여 최적화하였다. 각 변수의 경향을 분석한 결 과, 전체 스케일러 진동부를 구성하는 Head1, $\operatorname{Head} 2, \mathrm{Head} 3$ 부분과 Tail 부분은 길이가 늘어날 수록 중심주파수와 출력변위가 감소하는 사실을 알 수 있었다. 특히 각 부분의 길이 변화에 따라 Head3>Head2>Head1 > Tail로 Head3부분에서 가장 민감하게 주파수와 출력변위가 변화하는 사실을 알 수 있었다. 또한 팁과 $\mathrm{PZT}$ 의 직경은 고정되어 있기 때문에 팁과 $\mathrm{PZT}$ 가 연결되는 Head1과 $\mathrm{Head} 3$ 의 직경은 고정을 시켰다(표 1).

이와 같은 결과를 토대로 최적화 과정을 진행하 여 $28 \mathrm{kHz}$ 부근의 주파수에서(그림 5(a)) $20 \sim 30 \%$ 의 개선된 출력 변위(그림 5(b))를 얻었다. 

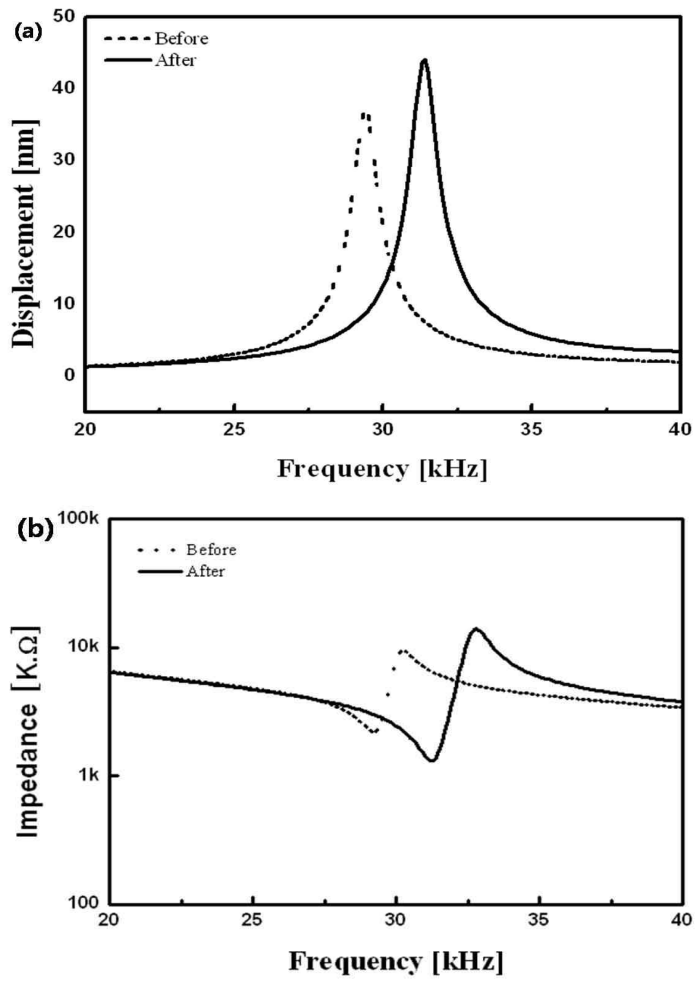

그림 5. (a) 출력변위 (b) 공진주파수

Fig. 5. (a) Displacement (b) Resonance frequency

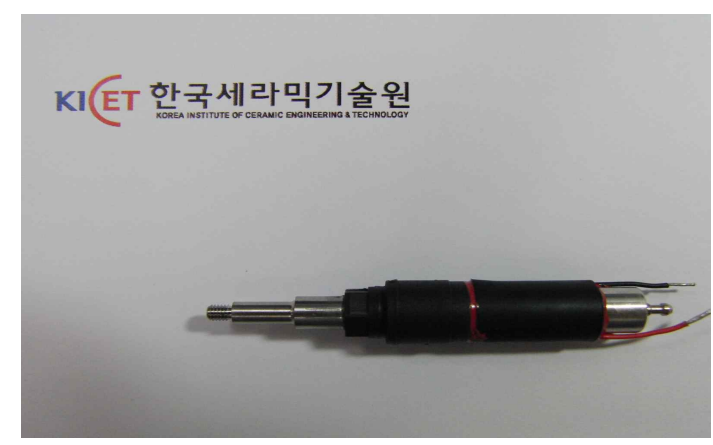

그림 6. 제작된 압전형 초음파 스케일러.

Fig. 6. Piezoelectric ultrasonic scaler produced.

\section{3. 스케일러 제작 및 평가}

시뮬레이션 최적화를 통해 선정 된 스케일러를 직접 제작하여 그 특성을 확인하고자 하였다(그림 6).

그림 6과 같이 제작된 스케일러의 특성을 평가 하기 위해 다음과 같은 방법을 이용하여 스케일러

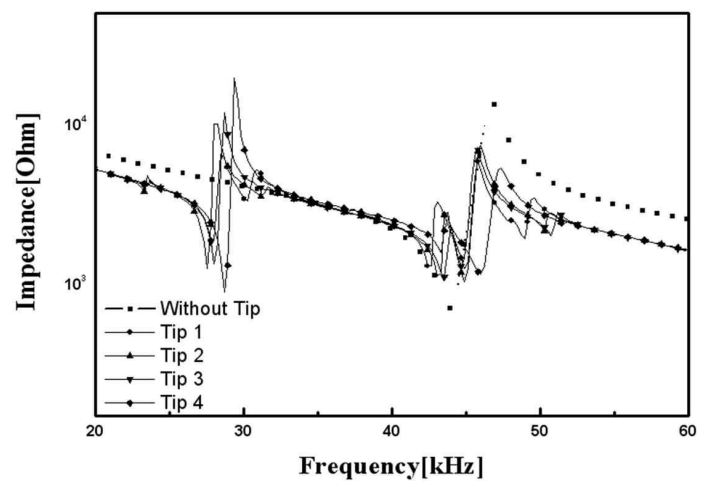

그림 7. Tip에 따른 주파수 변화(Impedance 4194A).

Fig. 7. Changing of frequency by several tips (Impedance 4194A).

의 주파수와 출력변위를 측정하였다. 첫 번째로 스 케일러 진동부에 팁의 부하영향을 측정하기 위해 스케일러 진동부에 그림 3의 Tip을 부착시킨 후에 Impedance 4914A장비를 이용하여 중심주파수를 측정한 결과, 기존 약 $30 \%$ 에서 팁의 영향에 비해 약 $3 \%$ 로 개선된 특성을 확인 하여 팁의 부하에 덜 영향을 받는 스케일러 진동부가 제작된 것을 확인 할 수 있었다(그림 7).

두 번째로는 스케일러 자체에서 발생하는 출력 변위를 측정하였으며 압전 세라믹 진동의 캐비테 이션(cabitat ion)[7] 효과 보다는 진동으로 팁이 부 딪치는 힘을 이용하기 때문에 구동 세기를 측정하 기 위해서 팁 끝에서 부딪치는 힘을 측정 할 수 있어야 한다. 압전형 초음파 스케일러의 출력변위 를 알아보기 위해 그림 8의 장비를 사용하였다. 그 림 8 은 출력 측정 시 진동자를 구동시키면서 분동 의 무게를 가해 일정 무게가 되면 진동자 끝의 팁 이 Linear bearing과 분동을 더 이상 밀어내지 못 하게 되고, 이때의 Linear bearing과 분동의 무게 에 중력가속도를 곱하면 진동자에서 출력 되는 힘 의 반이 되고 단위는 $\mathrm{N}$ (뉴턴)이 되어 진동자 출력 을 측정하는 장치이다. 제작된 스케일러의 진동자 의 최대 출력 실측치는 Linear bearing의 무게 $13 \mathrm{~g}$, 분동의 무게 $320 \mathrm{~g}$ 이므로,

$$
F=m a=(0.013+0.32) \times 9.8=3.2634 N
$$

식 (4)에 의해 약 $3.26 \mathrm{~N}$ 출력을 나타내었다. 일반 적으로 상용되는 스케일러의 경우 $3 \mathrm{~N}$ 이하의 출력 을 가지는 것에 비해 개발된 스케일러는 향상된 출력을 얻을 수가 있었다. 


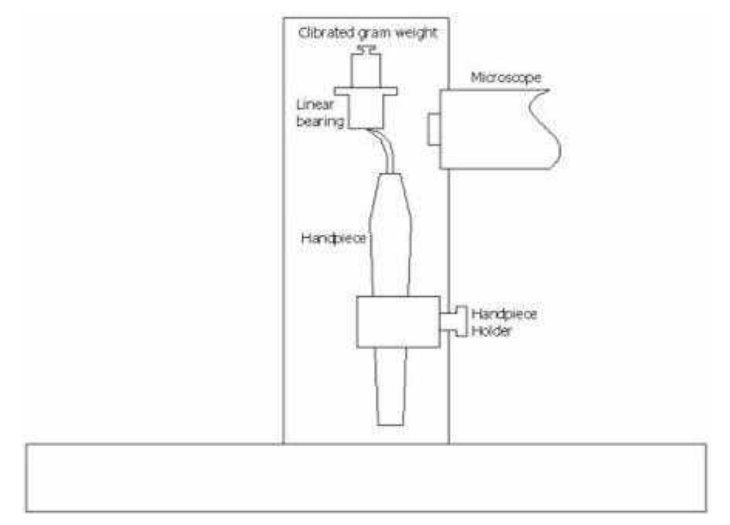

그림 8. 스케일러의 출력 측정장치.

Fig. 8. Measuring equipment of displacement of the scaler with tip.

\section{4. 결 론}

본 연구에서는 의료기기(치과용) 스케일러 개발 을 위하여 다음과 같은 단계를 진행하였다.

첫 번째로는 4개의 PZT를 사용하여 현재 상용 되는 스케일러의 Head, Tail부의 형상을 모델링하 였고 실제 제작된 모델과 시뮬레이션 모델의 임피 던스 특성을 비교하여 시뮬레이션의 유효성을 검 증하였다.

두 번째로는 유한 요소해석을 사용하는 ANSYS 시뮬레이션을 통하여 스케일러의 각 구성품, 즉 Head1, Head2, Head3의 길이와 직경변화에 따른 경향을 분석토대로 $\mathrm{Tip}$ 의 영향을 최소화하며 최고 수준의 출력변위를 가지는 최적 구조를 제안하였다.

세 번째로는 제작된 스케일러를 임피던스와 절 삭력과 같은 특성을 비교, 측정한 결과 $28 \mathrm{kHz}$ 대 역의 중심주파수를 가지며 $20 \sim 30 \%$ 향상된 출력 변위를 확인하였다.

다음의 분석결과들로 인해 초음파 스케일러를 체계적으로 규격화함으로써 Tip의 영향을 최소화 하는 진동부를 개발함과 동시에 현 상용제품 비교 했을 때 최고 수준의 출력변위를 가지는 압전형 초음파 스케일러를 개발하여 상용화 하였다.

\section{감사의 글}

본 연구는 중소기업기술혁신개발사업의 지원을 받아 수행되고 있으며, 이에 감사드립니다.

\section{참고 문헌}

[1] H. Kawashima, S. Sato, M. Kishida, and K. Ito, "A comparison of root surface instrumentation using two piezoelectric ultrasonic scalers and a hand scaler in vivo", J. Periodont. Res., Vol. 42, p. 90, 2007.

[2] T. F. Flemmig, G. F. Petersilka, A. Mehl, R. Hickel, and B. Klaiber, "The effect of working parameters on root substance removal using a piezoelectric ultrasonic scaler in vitro", Journal of Clinical Periodontology, Vol. 25, p. 158, 1998.

[3] T. F. Flemmig, G. F. Petersilka, A. Mehl, R. Hickel, and B. Klaiber, "Working parameters of a Magnetostrictive ultrasonic scaler influencing root substance removal in vitro", Journal of Periodontology, Vol. 69, p. 547, 1998.

[4] J. Garcia-Bonito, M. J. Brennan, S. J. Elliott, A. David, and R. J. Pinnington, "A novel high-displacement piezoelectric actuator for active vibration control", Smart Mater. Struct., Vol. 7, p. 31, 1998.

[5] S. C. Lea, G. Landini, and A. D. Walmsley, "Assessing the vibrations of dental ultrasonic scalers", Journal of Sound and Vibration, Vol. 271, p. 1113, 2004.

[6] Walmsley, A. D., Laird, W. R. E., and Williams, A. R., "Displacement amplitude as a measure of the acoustic output of ultrasonic scalers", Dental Materials, Vol. 2, p. 97, 1986.

[7] S. Jepsen, M. Ayna, J. Hedderich, and J. Eberhard, "Significant influence of scaler tip design on root substance loss resulting from ultrasonic scaling:a laserprofilometric in vitro study", J. Clin. Periodontol, Vol. 31, p. 1003, 2004.

[8] S. C. Lea, G. Landini, and A. D. Walmsley, "Ultrasonic scaler tip performance under various load conditions", J. Clin. Periodontol, Vol. 30, p. 876, 2003.

[9] E.-K. Lim, C.-I. Kim, Y.-J. Lee, J.-I. Im, and J.-H. Paik, "Effects of $\mathrm{Fe}_{2} \mathrm{O}_{3}$ addition on piezoelectric properties of $\mathrm{Pb}\left(\mathrm{Ni}_{1 / 3} \mathrm{Nb}_{2 / 3}\right) \mathrm{O}_{3}{ }^{-}$ $\mathrm{PbZrO}_{3}-\mathrm{PbTiO}_{3}$ ceramics for actuator applications, J. of KIEEME(in Korean), Vol. 19, No. 10, p. 935, 2006. 